\title{
La Rerum Novarum y su influencia en el catolicismo social peruano: La experiencia de los Círculos de Obreros Católicos (1891-1931)
}

\author{
Ricardo Cubas Ramacciotti ${ }^{1}$ \\ Recibido: 5 de marzo de 2017 - Aceptado: 14 de mayo de 2017
}

\begin{abstract}
Resumen
Pese a la influencia del catolicismo en el mundo popular peruano, son pocos los estudios sobre su participación en los movimientos obreros. Basado en diversas fuentes documentales, en este artículo se exploran algunas facetas y aportes del pensamiento social católico, junto con ciertas iniciativas desarrolladas para enfrentar la cuestión obrera entre 1891 y 1931. Para ello, se analiza la influencia de la encíclica Rerum Novarum y la adaptación del social cristianismo en el contexto latinoamericano y peruano. Luego, se examinan las ideas de algunos representativos líderes católicos respecto a las consecuencias de la modernización económica y la expansión capitalista en Perú. Finalmente, se estudian los Círculos de Obreros Católicos (COC), los cuales desarrollaron una experiencia asociativa donde se buscó generar una cultura y una identidad obrera cristiana que contribuyera a la mejora de las condiciones laborales de este sector y que contrarrestara la influencia de las ideologías radicales.
\end{abstract}

Palabras clave: Círculos de Obreros Católicos, historia de la Iglesia, Perú, pensamiento social peruano.

1 Peruano. Doctor en Historia, University of Cambridge, Reino Unido. Académico, Universidad de los Andes, Chile. Este trabajo pudo realizarse gracias al financiamiento del Fondo de Ayuda a la Investigación (FAI: INOTO201036 HIS-001-10) que la Dirección de Investigación de Universidad de los Andes, Chile, otorgó al autor. En relación a este artículo, dichos fondos sirvieron para hacer estadías de investigación en archivos peruanos donde se encontraron diversos documentos que contenían información inédita. Ello permitió al autor modificar propuestas y conclusiones de algunos de sus trabajos previos sobre el tema y actualizar la bibliografía, especialmente respecto a Cubas Ramacciotti, 2008. Agradezco también los valiosos aportes y sugerencias de los evaluadores ciegos, los cuales se han incorporado en el presente texto. E-mail: rcubas@uandes.cl 


\title{
Rerum Novarum and its influence on Peruvian social Catholicism: The experience of the Círculos de Obreros Católicos (1891-1931)
}

\begin{abstract}
Despite the influence of Catholicism in the Peruvian popular world, there are few studies addressing the Peruvian participation in workers' movements. According to various sources, this article explores the contributions and phases of Catholic social thinking and some initiatives developed to address the workers' labor problems between 1891 and 1931. To this end, we analyze the influence of the Rerum Novarum encyclical and the adaptation of social Christianity in Latin American and Peruvian contexts and review ideas of some representative Catholic leaders regarding the consequences of economic modernization and capitalist expansion in Peru. Finally, we study the Círculos de Obreros Católicos (COC, for the Spanish acronym) which developed an associative experience in order to generate a culture and a Christian worker identity that contributed to the improvement of the sectorial working conditions and that counteracted the influence of radical ideologies.
\end{abstract}

Keywords: Circles of Catholic Workers, Church History, Peru, Peruvian Social Thinking.

\section{A Rerum Novarum e sua influência no catolicismo social peruana: a experiência dos Círculos de Obreros Católicos (1891-1931)}

\section{Resumo}

Apesar da influência do catolicismo no mundo popular peruano, existem poucos estudos sobre a sua participação nos movimentos operários. Com base a diversas fontes documentais, neste artigo se exploram alguns aspectos e contribuiç̧ões do pensamento social católico, conjuntamente com certas iniciativas desenvolvidas para abordar a questão obreira entre 1891 e 1931. Para fazer isso, analisa-se a influência da Encíclica Rerum Novarum e a adaptação do social cristianismo no contexto latino-americano e peruano. Em seguida, são examinadas as ideias de alguns líderes católicos representativos sobre as decorrências da modernização económica e de expansão capitalista no Peru. Finalmente, são estudados os Círculos de Obreros Católicos (COC), que desenvolveram uma experiência associativa onde procurou-se gerar uma cultura e uma identidade obreira cristã que contribuísse para melhorar as condições de trabalho deste sector para neutralizar a influência das ideologias radicais.

Palavras-chave: Círculos dos Obreiros Católicos, História da Igreja, Peru, pensamento social peruano.

Entre las décadas de 1970 y 1980 la historia del movimiento obrero en el Perú atrajo el interés de un importante grupo de investigadores, quienes estudiaron el origen de las organizaciones sindicales y sus relaciones con los 
partidos radicales, el Estado, las elites, los intereses económicos internacionales y las corporaciones extranjeras². Esta corriente historiográfica, si bien analizó temas antes inexplorados en la historia social del país, excluyó algunos aspectos importantes para la comprensión de la cultura obrera. Indudablemente uno de ellos fue el papel de la religión. Tal como ha sido descrito por Carl Strikwerda para el caso belga, una de las razones que explican esta omisión en Perú es que, desde ciertos presupuestos ideológicos, "se asumió que el socialismo representaba la auténtica ideología de la clase obrera". En este sentido, las otras organizaciones de trabajadores escondían un proyecto fundamentalmente conservador y, por lo tanto, eran incapaces de forjar una auténtica identidad de clase y no tenían la capacidad de ser representativas de sus demandas laborales (Strikwerda, 1988: 333).

Este enfoque se aplicó al catolicismo peruano de principios del siglo veinte, el cual fue caracterizado como un aliado incondicional de la oligarquía y como un elemento legitimador del statu quo ${ }^{3}$. Desde esta perspectiva, la Iglesia, tanto su jerarquía como sus fieles, fue vista como un instrumento de dominación de las clases populares y un obstáculo para el desarrollo de una sociedad democrática ${ }^{4}$. Las obras de beneficencia y de caridad de instituciones católicas tendieron a ser calificadas como «paternalistas» por no promover

2 Entre los textos más importantes sobre los orígenes y desarrollo inicial del movimiento obrero peruano destacaron: Basombrío Iglesias, 1982; Basombrío Iglesias y Sagástegui L., 1984; Blanchard, 1982; Melgar Bao, 1980; Pareja Pflucker, 1985; Portocarrero, 1987; Sulmont, 1975a. Los ensayos compilados por Stein y Miller analizaron diversos aspectos del mundo obrero peruano: S. Stein \& Miller, 1986. Flores Galindo (1983) examinó el caso de los mineros de Cerro de Pasco. Asimismo, se estudió la influencia de los movimientos radicales en el sindicalismo peruano, como fue el caso del anarquismo (Pareja Pflucker, 1980; Tejada, 1988); el aprismo (Pareja Pflucker, 1980; S. J. Stein, 1980) y el marxismo (Balbi \& Parodi, 1984; Balbi Scarneo, 1989; Sulmont, 1975b). Uno de los estudios más recientes sobre el movimiento obrero es el libro de Paulo Drinot, La seducción de la clase obrera: trabajadores, raza y la formación del Estado peruano (2016). Allí, desde una perspectiva influenciada por las teorías de Michel Foucault, se plantea que las políticas de industrialización, junto con las leyes e instituciones laborales diseñadas por el Estado y las élites peruanas, tuvieron como objetivo crear un nuevo modelo de "nación civilizada" que activamente buscó transformar, moldear y excluir el componente indígena del mundo laboral y de la formación cultural del país (Drinot, 2011).

3 Esta visión estuvo presente en algunos de los más influyentes historiadores sociales de las décadas de 1970 y 1980, como fueron Manuel Burga y Flores Galindo: "¿Qué elementos definirían a esta mentalidad oligárquica? En primer lugar, el catolicismo. La religión, como en la época colonial, se encuentra presente en los principales actos de la vida social. Es uno de los elementos que vinculan a los oligarcas con las clases subalternas... El catolicismo protegía a la sociedad oligárquica de cualquier amenaza externa proponiendo un ideal de "perfección" y "ventura" individual". (Burga y Flores Galindo, 1994: 91).

4 En buena medida estos presupuestos estuvieron influenciados por las duras críticas de Manuel González Prada contra el catolicismo. En su famoso libro Horas de Lucha sostenía: "hoy el Catolicismo figura como el aliado inevitable de todos los opresores y de todos los fuertes: donde asoma un tirano, cuenta con dos armas: la espada del militar y la cruz del sacerdote" (González Prada, 1964: 54). 
una opción revolucionaria de transformación de las estructuras sociales y más bien centrarse en la ayuda asistencial a sectores y personas necesitadas.

Este trabajo plantea una visión alternativa respecto a dichas perspectivas a partir de un estudio preliminar sobre el papel del catolicismo en el mundo obrero peruano entre 1891 y 1930. Al igual que en otros países de América Latina, durante este periodo el país experimentó un proceso de modernización económica y de expansión capitalista que produjo un cambio en las condiciones sociales. En este contexto, las antiguas formas de caridad de la Iglesia resultaban insuficientes frente a una nueva realidad en la cual las relaciones y demandas laborales se transformaban aceleradamente y donde las ideologías de corte radical empezaban a expandirse en los sectores populares 5 .

En esta línea, el presente estudio analiza las propuestas de reforma social desarrolladas por algunos líderes y asociaciones católicas frente a los problemas del mundo laboral peruano de la época. Para ello, primero se analiza la influencia de la encíclica Rerum Novarum y la adaptación de los principios del catolicismo social al contexto peruano. Luego se examina el pensamiento social católico frente a la cuestión obrera en el país. Finalmente, se estudia la formación y desarrollo de una de las principales iniciativas católicas en el mundo laboral peruano: los Círculos de Obreros Católicos (en adelante, COC).

\section{La Rerum Novarum y el catolicismo social latinoamericano}

Durante las primeras décadas del siglo XX el pensamiento social católico en el Perú estuvo notablemente influenciado por los principios esbozados en la encíclica Rerum Novarum de León XIII, publicada en 1891. Muchos fieles consideraron a este documento como la carta magna de los movimientos obreros católicos y como una guía para la acción social. La Rerum Novarum trajo consigo una toma de posición frente a los estragos causados por el proceso de industrialización sobre la clase obrera, junto con una condena a la explotación capitalista y a los principios individualistas y materialistas del sistema. En esta línea se defendieron una serie de derechos laborales que incluían el salario justo, condiciones de trabajo adecuadas y el derecho a formar asociaciones obreras. Paralelamente se condenaron también a los movimientos socialistas por su carácter secularizador y por promover una

5 Para el caso chileno, Macarena Ponce de León analiza cómo el proceso de modernización en el país condicionó una transformación en la forma de entender los conceptos de pobreza, caridad y beneficencia. Asimismo, ella examina los nuevos enfoques e iniciativas desarrollados por el Estado y la Iglesia Católica para enfrentar las consecuencias sociales y económicas de la industrialización y la expansión urbana en el Chile decimonónico (Ponce de León, 2011). 
opción revolucionaria violenta, la lucha de clases, la sustitución de la propiedad privada por la colectiva, y la interferencia arbitraria del Estado en la vida cotidiana de las personas ${ }^{6}$.

En dicho documento el Papa convalidó el pensamiento y la acción social llevada a cabo por muchos católicos en Europa, empeñados en crear estructuras que ayudaran a desarrollar condiciones de vida más humanas para las clases afectadas por la expansión del capitalismo industrial. Durante el siglo XIX surgieron en el mundo católico numerosas iniciativas de empresarios y de asociaciones obreras, que buscaron dar una respuesta a los problemas sociales planteando una alternativa frente a las propuestas de los movimientos socialistas inspirados en el marxismo. En las últimas décadas se han desarrollado estudios que han mostrado la importancia y la influencia del catolicismo social en varios países occidentales, especialmente en Bélgica, Alemania, Francia, España, Estados Unidos, y entre los sectores de la clase obrera de raíces irlandesas en el Reino Unido ${ }^{7}$. En estos países la presencia católica se manifestó en sindicatos confesionales, legisladores con avanzadas propuestas de reforma laboral, influencia en la opinión pública a través de la prensa, y la formación de partidos políticos. Las ideas y acciones desplegadas en los países industrializados sirvieron de modelo para los católicos latinoamericanos.

En América Latina, el catolicismo social tuvo un notable desarrollo en los países donde el proceso de industrialización fue más acentuado. Por ejemplo en Argentina se fundó el primer COC en Buenos Aires en 1892, y hacia 1912 ya existían 77 grupos similares con 22.930 afiliados y 21 edificios propios (Lynch, 1991: 114). Posteriormente se crearon primero la Liga Social Argentina y luego la Unión Popular Argentina, las que promovieron diversas actividades relacionadas con la difusión de los principios del catolicismo social, así como el apoyo a los sindicatos católicos. En México, el catolicismo social fue promovido activamente por obispos, sacerdotes y laicos a través de congresos y asociaciones católicas que proponían reformas laborales para el sector industrial y, al mismo tiempo, propuestas de cambio en el mundo rural ${ }^{8}$. Dos ejemplos de esto fueron el Partido Católico Nacional, fundado en 1911, el cual promovió importantes reformas sociales, y la Confederación Obrera

6 León XIII, 1891 § 10, 55

7 Para un estudio panorámico del catolicismo social en Europa pueden revisarse: Misner, 1991; Pazos, 1993; Vidler, 1964. Para el caso de España: Aldea Vaquero, García Granda, y Martín Tejedor, 1987; Castillo, 1977; Montero García, 1983. El caso de Irlanda es estudiado en O'Leary, 2000. Un estudio interesante sobre el catolicismo social en Francia lo podemos encontrar en Gibson, 1989. El caso de los sindicatos belgas es estudiado por Carl Strikwerda, 1988. Un interesante artículo sobre el catolicismo social en los Estados Unidos lo encontramos en McCartin \& McCartin, 2007.

8 Para el caso mexicano, puede consultarse un detallado estudio sobre el catolicismo social en Ceballos Ramírez, 1991. 
Católica Nacional, la cual a principios de los años 20 tuvo gran influencia en el mundo rural. Sin embargo, muchas de las iniciativas católicas fueron reprimidas violentamente durante la Revolución Mexicana, que trajo consigo, entre otras cosas, una polarización religiosa en este país (Lynch, 1991: 119).

En el caso del Perú, los principios de la doctrina social de la Iglesia y de la Rerum Novarum tuvieron que aplicarse a una realidad radicalmente distinta a la de Europa. Hacia 1930 el proletariado industrial era aún una minoría y la mayor parte de la población económicamente activa estaba dedicada a la agricultura. A pesar de ello, desde 1890 el Perú participó del proceso de modernización mundial desde la periferia, principalmente como exportador de materias primas. Ello supuso una diversificación de su producción y el surgimiento de nuevas industrias en Lima y otras ciudades principales del país (Klarén, 2004: 255-256).

Estos procesos contribuyeron a que la sociedad peruana experimentara cambios acelerados. La relativa estabilidad política de la época y las transformaciones económicas habían generado nuevas oportunidades laborales que alentaron la migración del campo a la ciudad. Así, como señalan Cueto y Contreras, si bien no se realizó un censo nacional general entre 1876 y 1940 , algunos censos regionales revelan que hubo un importante aumento de la población en los principales centros urbanos del país. En el caso de Lima, la población creció de aproximadamente 115.000 habitantes en 1890 a cerca de 380.000 en 1931. En 1908 el 58\% de la población limeña no había nacido en la ciudad y cerca del $10 \%$ era extranjera. Otras ciudades como Arequipa, Cuzco y Trujillo también crecieron, aunque a un ritmo más lento respecto a la capital (Contreras, C. y Cueto, M., 2013: 231-232).

Este fenómeno hizo que la población urbana del país fuera más diversa desde el punto de vista étnico y más cosmopolita. Asimismo, trajo consigo una expansión de la clase obrera y la aparición de nuevos problemas sociales, como la falta de una adecuada legislación laboral, condiciones de vivienda precarias, bajos salarios, falta de cobertura educativa, entre otros. Del mismo modo, la expansión económica al interior del país generó desequilibrios en el mundo rural. Por ejemplo, las nuevas inversiones mineras en la sierra central, la explotación del caucho en la región amazónica y el comercio de lanas en la sierra sur, descompusieron, en muchos casos dramáticamente, la vida de las comunidades nativas en dichas regiones.

Desde principios del siglo XIX los obreros urbanos empezaron a organizarse en busca de reivindicaciones laborales que incluían la jornada de ocho horas de trabajo y mejoras salariales. Entre ellos destacaron los trabajadores dedicados a los rubros textil, transporte, minero, de las plantanciones azucareras y algodoneras y de producción de alimentos. En un principio estas organizaciones tuvieron un carácter mutualista, floreciendo así las sociedades de socorros 
mutuos. Luego, debido a la influencia de las nuevas corrientes ideológicas y a la expansión capitalista, el anarco-sindicalismo logró tener arraigo en el mundo obrero de Lima y en algunas ciudades de provincias, encabezando algunas de las protestas más importantes en favor de los derechos laborales (Klarén, 2004: 274-277). Ello quedó plasmado en círculos culturales obreros, obras de teatro y en publicaciones periódicas como El Oprimido, Los Parias, Plumadas de Rebeldía y, sobre todo, La Protesta. Varios intelectuales apoyaron estas acciones, como fueron los casos de Manuel González Prada, José Matías Manzanilla, Abelardo Gamarra y Francisco Mostajo (Contreras, C. y Cueto, M., 2013: 232-234). A pesar de ello, la influencia de este movimiento fue limitada y no logró generar una organización a nivel nacional, ni llegó a suplantar las sociedades de socorros mutuos.

Estas luchas laborales tuvieron eco en los gobernos. Así, en 1912 la presidencia de Guillermo Billinghurst buscó representar las reivindicaciones obreras del momento, utilizando como símbolo "el pan grande" e impulsando un conjunto de leyes laborales. Posteriormente, durante el segundo gobierno de José Pardo (1915-1919) se promulgó la ley general de las ocho horas de trabajo. Luego, durante la década de 1920, el presidente Augusto B. Leguía (1919-1930) estableció un nuevo tipo de régimen que dio fin al predominio del Partido Civil, presentándose como un defensor de los intereses de las clases medias, de los obreros y de las poblaciones indígenas. Este período estuvo caracterizado por la expansión del Estado y de las obras públicas, por una creciente tendencia al autoritarismo del gobierno y por una mayor organización de los movimientos obreros.

En estos años se desarrollaron dos tendencias de corte revolucionario: el marxismo y el aprismo. Ambos estuvieron profundamente marcados por dos figuras icónicas que se convirtieron en referentes centrales del pensamiento político del Perú en el siglo XX: José Carlos Mariátegui (1894-1930) y Víctor Raúl Haya de la Torre (1895-1979). Después de la crisis económica mundial de 1929 y de la caída de Leguía en 1930, ambas opciones políticas lograron un mayor arraigo e influencia en las organizaciones sindicales del país, sin embargo, estuvieron lejos de tener un poder monopólico sobre ellas.

Los cambios en la estructura social, laboral y económica del país, el avance de las nuevas ideologías en la clase obrera, el ejemplo de movimientos similares en el mundo católico y el ascendiente del magisterio pontificio fueron elementos esenciales para el desarrollo del catolicismo social en el Perú. Así, desde la década de 1890 se dieron un conjunto de iniciativas llevadas a cabo tanto por la jerarquía como por los laicos que buscaron de una u otra manera enfrentar el tema obrero y otros problemas sociales del país. Testimonio de ello fueron la formación de los COC y de asociaciones laicas, y la participación de la Iglesia en el Patronato de la Raza Indígena desde 1922. Esto se dio en un contexto de renovación de la Iglesia en el Perú, caracterizado por la or- 
ganización de un laicado militante, la llegada de numerosas congregaciones religiosas extranjeras y la presencia de una notable e influyente generación de obispos 9 .

Es importante notar que el catolicismo social promovió un orden cristiano inspirado en la doctrina social de la Iglesia que proponía una alternativa de reforma frente a los movimientos de corte revolucionario y radical, los cuales, especialmente en sus versiones marxista y anarquista, buscaban establecer un modelo de sociedad secular que tendía a ser militantemente hostil contra la religión.

El catolicismo social planteaba una posición crítica frente a muchas de las consecuencias sociales generadas por la expansión del capitalismo industrial y, a partir de una reflexión ética sobre la dignidad humana y el trabajo, más que un modelo específico, proponía lineamientos de pensamiento y de acción que debían ser aplicados a las situaciones concretas de la sociedad y del país. En este sentido, a diferencia de las ideologías radicales, un orden social cristiano no suponía el establecimiento de un sistema político y económico determinado sino el respeto de un conjunto de principios, como la primacía de la dignidad humana, el reconocimiento de la propiedad privada, el papel subsidiario del Estado, la protección de los derechos de los trabajadores y de la familia, la libertad de asociación, entre otros. De este modo, dichos lineamientos debían ser aplicados de manera diversa, según las circunstancias y la realidad cultural, social y política de cada pueblo.

\section{El pensamiento social católico peruano y la cuestión obrera}

El tema social fue parte esencial del discurso de numerosos líderes católicos peruanos, tanto eclesiásticos como laicos. Entre los más destacados estuvieron los obispos Pedro Pablo Drinot (Obispo de Huánuco y luego Obispo Auxiliar de Lima $^{10}$, Mariano Holguín (Arequipa) y Pedro Farfán (Obispo de Cusco y luego Arzobispo de Lima). Entre los sacerdotes fueron importantes Isaías Vargas, un canónigo del Cusco con numerosos escritos sobre el problema indígena en el sur peruano"11, el canónigo Mariano García y el franciscano Francisco Cabré, quien como director del periódico La Colmena, analizó metódicamente

9 Un análisis de este resurgimiento católico se encuentra en el tercer capítulo de Klaiber, 1988.

10 Drinot publicó numerosas cartas pastorales sobre el tema social. Un importante documento donde hace una síntesis de sus ideas sociales es: Drinot, 1928.

11 Algunos de sus ensayos más importantes están recopilados en los siguientes libros: Vargas, 1936, 1947, 1948 y 1952. 
los problemas obreros del país. Entre los laicos más activos destacaron Carlos Elías, uno de los principales organizadores del Primer Congreso Católico Peruano de 1897, Carlos Polar'21, y numerosos políticos que en algún momento llegaron a ser parte de la Unión Católica, una organización laica que tuvo una dimensión nacional ${ }^{13}$. Probablemente el intelectual que elaboró una visión más sistemática del Perú desde una inspiración católica fue Víctor Andrés Belaunde, especialmente en obras como La Realidad Nacional y Peruanidad. Desde el punto de vista oficial, la jerarquía de la Iglesia Católica en el Perú se pronunció sobre el tema obrero y otros aspectos sociales en varios documentos colectivos de la Asamblea Episcopal ${ }^{14}$, en los Concilios Limenses (VII Concilio Limense, 1913; VIII Concilio Limense, 1934) y en otros congresos ${ }^{15}$.

Si bien existen algunas diferencias en los acentos y planteamientos entre ciertos obispos, sacerdotes y laicos, es posible delinear algunas ideas comunes. Un primer aspecto es que la acción social católica era entendida como una consecuencia de la vivencia de la fe cristiana, lo cual ineludiblemente implicaba la práctica de la caridad y la búsqueda de la justicia frente a las necesidades y carencias de las personas y la sociedad ${ }^{16}$. En esta línea se sostenía que la acción de la Iglesia no debía confinarse al ámbito privado, sino que ella tenía el derecho y el deber de participar en la esfera pública para transformar la sociedad según las exigencias del evangelio. Especialmente a partir del pontificado de San Pío X (1903-1914) se sostenía que todos los católicos debían contribuir en la construcción del reinado social de Jesucristo (Asamblea Episcopal del Perú, 1922: 11).

12 Rector de la Universidad San Agustín de Arequipa y senador por este departamento entre 1895-1899. Fue uno de los fundadores y el primer jefe de redacción del periódico católico El Deber. Sus ideas con respecto a la clase obrera están resumidas en una de sus conferencias: Polar, 1912.

13 Algunos de ellos fueron el presidente Eduardo López de Romaña, Pedro José Rada y Gamio, Evaristo Gómez Sánchez y Felipe Varela y Valle.

14 Dos documentos importantes son: Asamblea Episcopal del Perú, 1905; Asamblea Episcopal del Perú, 1922.

15 Entre ellos destacó el Primer Congreso Interdiocesano de Acción Social que se realizó en Cusco en 1921. Aquí se reunieron representantes de las diócesis de Cusco, Arequipa, Ayacucho y Puno para reflexionar, entre otros temas, acerca del problema indígena y obrero. Ver: Primer Congreso Interdiocesano de Acción Social, 1921.

16 "La acción social católica ha de ser eminentemente obra de amor y llevar el sello de la caridad cristiana, porque Jesucristo, maestro divino del mundo, dijo en su Evangelio: este es el precepto mío, que os améis los unos a los otros. El amor a Dios y a las almas ha de ser, pues, el móvil y el alma de esta obra social religiosa.... Esta caridad debe ser fecunda en beneficios principalmente hacia los oprimidos, los débiles, ignorantes y desamparados. Debe ser industriosa y diligente para estudiar y remediar con prudencia y eficacia las verdaderas necesidades del pueblo cristiano. En este sentido la acción católica se manifiesta con múltiples y variadas obras de preservación, propaganda y protección preferentemente populares en favor del niño, del obrero, del huérfano, de la familia, del enfermo, de los extraviados y hasta de los criminales" (Asamblea Episcopal del Perú, 1922: 14-15). 
Otro rasgo fue el carácter apologético. Existía la percepción de que la presencia de la Iglesia y de la identidad católica del Perú estaba siendo minada tanto por las ideologías radicales como por el avance del protestantismo. Se consideraba que el ethos católico constituía un aspecto esencial de la peruanidad y que por ello estas influencias no sólo atentaban contra la ortodoxia sino que eran fuerzas desintegradoras de la nacionalidad ${ }^{17}$. Había un constante llamado a los laicos a llevar a cabo una militante defensa de la presencia católica en el país y a combatir las nuevas influencias que atentaran contra la misma, en especial, el marxismo y el anarquismo. En esta línea, se criticaron los planteamientos revolucionarios que fomentaban la lucha de clases y el uso de la violencia para lograr el cambio de las estructuras ${ }^{18}$. Frente a ello se sostenía que era necesario lograr, a través de varios medios, una reconciliación entre el capital y el trabajo. En numerosos escritos se enfatizaba la necesidad de crear medios a través de los cuales empresarios y obreros pudieran llegar a acuerdos convenientes a ambos y que sirvieran para evitar enfrentamientos violentos ${ }^{19}$.

17 La percepción de muchos católicos de que la Iglesia estaba siendo asediada no era del todo inexacta. Desde fines del siglo XVIII los Borbones habían iniciado un proceso secularizador que fue acentuándose en América Latina luego de la independencia. En varios de estos países el liberalismo decimonónico estuvo acompañado de un radical anticlericalismo que trajo consigo confiscaciones de tierras, una constante intervención estatal en aspectos propios de la disciplina eclesiástica y, en algunos casos, persecuciones contra miembros del clero y laicos comprometidos. Es necesario resaltar que la mayor parte de los proyectos secularizadores de los siglos XVIII y XIX habían sido dirigidos por el Estado y un sector de la élite. Si bien ellos fueron el primer paso para la llegada de otras influencias al Perú, la catolicidad del pueblo se mantuvo casi inalterada durante el siglo XIX. Esta situación empezó a cambiar con el arribo de nuevas ideologías radicales, en especial del anarquismo y luego del marxismo. Ellas representaron para el catolicismo una nueva amenaza debido a que, junto con sus tendencias laicistas y antirreligiosas, lograron tener un carácter netamente popular. Ambos movimientos se presentaron como redentores de la clase obrera y, por lo tanto, como una opción alternativa frente a la fe cristiana. De otro lado el protestantismo fue también percibido como una poderosa amenaza debido a varias razones. En primer lugar, desde el Virreinato el catolicismo había sido la religión de casi la totalidad de la población. La llegada del protestantismo necesariamente traería el fin de esta situación debido a su influencia en algunos sectores populares del país. En segundo lugar, se consideraba a los protestantes como aliados (o instrumentos) de los liberales y de la masonería. En tercer lugar, muchos protestantes que llegaron al país tenían una tendencia anticatólica expresada en sus prédicas. Un testimonio de ello puede verse en las apreciaciones sobre el catolicismo peruano de Geraldine Guinness, una misionera protestante británica (1909).

18 Existen numerosos documentos que respaldan esta afirmación. Un ejemplo lo encontramos en Bermejo, 1914: 10-11.

19 Un ejemplo de ello se puede ver en el VIII Concilio Limense, donde se enfatizó la necesidad de lograr una reconciliación de las clases sociales: "Lamenta la Iglesia la falta de justicia y caridad cristiana con que algunos capitalistas, olvidados de Dios y adoradores del becerro de oro, oprimen a la clase trabajadora, así como también los excesos a que llegan algunas organizaciones obreras, que no contentas con reclamar con medios legales sus derechos, perturban a menudo, con huelgas ilícitas, la vida de los pueblos, mantienen vivo el odio de clases, y amenazan trastrocar violentamente el orden natural de la sociedad, y recomienda, 
Esto no significó una actitud indiferente ante los excesos del capitalismo ni tampoco la difusión de una actitud de resignación frente a las condiciones económicas y laborales vigentes. Antes bien hubo severas condenas a la explotación del obrero y se promovieron reformas laborales. Por ejemplo el franciscano Francisco Cabré sostenía que:

"El capital sin entrañas que trata de crecer desmesuradamente a toda costa, importándole poco que las ruedas de su carro triunfal arrollen miles y miles de proletarios y otros tantos hogares que tienen derecho a la felicidad; no tiene reparo en abusar de la debilidad del niño y de la mujer, explotando brutalmente su trabajo y desorganizando el hogar obrero con gravísimo daño para la sociedad en general."

Así mismo el canónigo Mariano García, asesor espiritual del COC del Cusco, afirmaba que las asociaciones de obreros debían tener personalidad jurídica para exigir salarios justos y las demás consideraciones impuestas por la ley natural. Sin embargo, García señalaba que en la mayor parte de los casos estas condiciones no se daban, pues:

"impunemente y con facilidad sorprendente y reprobable, los grandes capitalistas y empresarios de industrian saltan, sin derecho alguno, por encima de las leyes de la justicia, aparte de imponer a sus operarios y empleados un yugo que difiere poco del de los esclavos, como dice el Pontífice citado, y darles un trato que pugna abiertamente con la dignidad humana que por derecho natural exige amor, respeto y consideraciones morales" (García, 1913b: 7-8).

En concreto, García hacía referencia a los abusos presentes en las minas del Perú y también aludió directamente a los problemas que se habían dado en la selva peruana, mencionando el escándalo del Putumayo (García, 1913a: 9). Frente a esta situación se sostenía que si los obreros no encontraban un tribunal o árbitro ad hoc para alcanzar la efectividad de su justa demanda, ellos podrían optar con razón jurídica por las solicitudes colectivas, guardando las leyes de la moral como medio imprescindible y obligatorio para ejercer presión sobre sus patrones. Uno de los medios legítimos para defender sus derechos era la huelga. Sin embargo, ella no debía estar acompañada de violencia ni de destrucción de la propiedad privada (García, 1913b: 13). En muchas ocasiones se exhortó a los obreros a contribuir a modificar la legislación laboral existente haciendo oír su voz en el municipio y en el parlamento (Cabré, 1918: 14).

tanto a los patrones como a los obreros, que para solucionar el problema social, busquen en los preceptos del Evangelio y la práctica de las virtudes cristianas, la necesaria armonía de clases, fundada en el respeto a las normas inflexibles de la justicia y a los dictados de la caridad". Ver VIII Concilio Limense, 1934: § 208. 
En sintonía con algunos de los movimientos de obreros católicos en Europa se proclamaron una serie de derechos como el del salario justo, el seguro obrero y el derecho a asociación de los trabajadores. Las asociaciones obreras debían convertirse en un espacio de mutua solidaridad, de formación cristiana y de protección de los derechos laborales (La Colmena, 19-III-1920). Sin embargo, se consideró que las asociaciones obreras no debían limitarse a protestar contra el sistema sino que debían generar proyectos sociales que coadyuvaran al desarrollo económico, cultural y moral de sus miembros. Para ello era indispensable la promoción del cooperativismo y el mutualismo. Esto incluía la formación de una red de promoción social que incluía socorros mutuos, cajas de ahorro, proyectos habitacionales y escuelas nocturnas (Cabré, 1918: 17-20).

Al mismo tiempo, en contraposición con los movimientos marxistas, hubo una decidida defensa del principio de la propiedad privada y se señaló que el obrero debía tener un salario que le permitiera tener un excedente para el ahorro. A partir del ahorro, eventualmente el obrero estaría en la capacidad de ser propietario, lo cual se convertiría en un medio de progreso económico esencial. Sin embargo, el derecho a la propiedad no era considerado absoluto (Cabré, 1918: 17-20). En situaciones en que el bien común lo requería se consideraba justificable limitar la propiedad privada pero con una indemnización proporcional al afectado.

También se enfatizó la necesidad de crear una cultura popular obrera que fuera netamente cristiana. Ello implicaba necesariamente promover una labor educativa que ayudara a evangelizar a las clases trabajadoras y que al mismo tiempo generara hábitos, como los del ahorro y la honradez, considerados necesarios para el desarrollo integral de las mismas ${ }^{20}$. Ello también supuso que se buscara desterrar algunos vicios, como por ejemplo el alcoholismo, a través de la formación de ligas de temperancia. La creación de bibliotecas populares y de una prensa católica obrera eran vistas como elementos esenciales para este fin. Con estas actividades se buscó impartir una formación intelectual católica y cívica, crear una identidad obrera consciente de sus derechos y a la vez brindar conocimientos técnicos y criterios morales que pudieran ser aplicados en la vida cotidiana (La Colmena, 17-IV-1921). La identidad obrera debía ser reforzada a través de un conjunto de actividades que debían incluir conferencias, obras teatrales, concursos literarios y la participación en eventos recreativos y deportivos (Asamblea Episcopal del Perú, 1922: 134-135).

Otro elemento común fue la exaltación del patriotismo a través de actos cívicos. En esta línea se buscó que, en la medida de lo posible, las asociaciones obreras tuvieran relaciones armónicas con el Estado. Sin embargo, esto

20 Ambos aspectos se resaltan en la siguiente conferencia dada en el COC de Arequipa: Margañón, 1912. 
no significó que en ciertas ocasiones no surgieran posiciones críticas frente a las acciones gubernamentales consideradas lesivas para el orden social21.

\section{Formación y desarrollo de los Círculos de Obreros Católicos en Perú22}

Durante la década de 1890 el pensamiento social católico en el Perú buscó plasmarse en obras concretas que tuvieran impacto en el mundo obrero. Entre ellas probablemente las más importantes fueron los COC los cuales fueron creados por obispos, religiosos o laicos y tuvieron desde el principio el decidido apoyo de la jerarquía eclesiástica²3. El 19 de marzo de 1896 el fraile franciscano Mariano Holguín fundó el Círculo de Obreros Católicos de Arequipa (en adelante, CCA) convirtiéndose así en el pionero del movimiento laboral católico en el Perú. A partir de esa fecha y en base a este modelo se crearon otras organizaciones similares en el Perú a lo largo de las tres primeras décadas del siglo XX. En el Congreso Católico Peruano, reunido en Lima en noviembre de 1896, donde obispos, sacerdotes y laicos elaboraron planes pastorales a nivel nacional, se consideró al CCA como un modelo a seguir en otras regiones del país y se sugirió que estas instituciones tuvieran una coordinación nacional aunque manteniendo su independencia (Primer Congreso Católico del Perú, 1897: 6). Así, durante los siguientes años fueron creados COC similares al menos en las ciudades de Cusco, Lima, Ayacucho, Trujillo, Puno y Huanta.

Los COC siguieron patrones de organización parecidos y sus metas y contenidos doctrinales fueron similares ${ }^{24}$. Buscaron tener personalidad jurídica y poseían un estatuto que los regulaba, el cual habitualmente establecía que los COC estarían regidos por un consejo directivo elegido por una asamblea general donde todos los miembros activos tenían derecho a voto. Existían tres clases de miembros, los socios activos, los protectores y los honorarios. Los primeros eran los obreros que se incorporaban a los COC y tenían pleno derecho a voto. Entre los requisitos más importantes estaban el ser católico,

21 Por ejemplo, a pesar de los estrechos vínculos con el presidente Augusto B. Leguía, La Colmena, el periódico del COC de Arequipa, criticó algunos aspectos de la polémica ley de conscripción vial. Ver La Colmena, 27-VI-1925.

22 Lamentablemente para el presente estudio no se ha tenido acceso a testimonios directos de los obreros que participaron de los COC. Sin embargo, aspectos de su vida cotidiana han sido retratados en los periódicos de dichas instituciones, en especial en La Colmena, donde ocasionalmente se publicaron listas de nombres de los miembros.

23 En todos los documentos de la Asamblea Episcopal y de los Concilios Limenses de 1912 y 1927 se reafirma este apoyo.

24 Podemos afirmar esto en base a la información recogida en los periódicos católicos La Colmena y La Hormiga, y a los estatutos encontrados del CCA (Círculo de Obreros Católicos de Arequipa, 1901, 1922). 
tener un oficio honrado y tener por los menos dieciséis años de edad. Los socios protectores eran personas que sin ser obreros pasaban a ser parte del COC para apoyarlo económicamente con una cuota mensual y colaborando en las actividades de la asociación. Los socios honorarios eran nombrados por la Junta Directiva por "sus méritos personales y su servicio a la clase obrera" (Círculo de Obreros Católicos de Arequipa, 1922: art 11).

Con la incorporación de los socios protectores y de los socios honorarios se buscaba la cooperación entre capital y trabajo por medio del compromiso de sectores de la élite y, al mismo tiempo, conseguir el apoyo del Estado para algunas de sus actividades. En algunos casos, los cargos de presidentes honorarios estaban ocupados por influyentes políticos como fueron los casos de Pedro José Rada y Gamio (La Colmena, 17-IV-1921), quien siendo Ministro de Fomento en 1921 fue presidente honorario del CCA, o Augusto B. Leguía, quien ocupó el mismo cargo en el COC de Puno en 1930 (La Colmena, 15-II-1930). El vínculo formal con la jerarquía se establecía a través del director eclesiástico, el cual solía ser propuesto por los miembros de los COC y aprobado por el obispo de la ciudad. En la mayor parte de los casos el director eclesiástico tuvo una importante influencia en los COC, no sólo como consejero espiritual sino como promotor en el desarrollo de actividades sociales y culturales. Por ejemplo, el P. Francisco Cabré O.F.M. cumplió un papel esencial en el desarrollo del CCA, siendo el encargado de redactar sus estatutos en 1922 y dirigiendo el periódico de esta institución. A pesar de los vínculos con un sector de la élite, el gobierno y la jerarquía eclesiástica, la dirección y el desarrollo de los COC estuvieron en manos de los miembros activos. Eran ellos quienes en las juntas generales elegían anualmente a toda la junta directiva, la cual generalmente incluía a un presidente, un vicepresidente, un secretario, un tesorero, un número variable de vocales y los directores de las ramas que tuviera el circulo.

Como puede verse en los estatutos y en las publicaciones de los COC, sus fines principales fueron la evangelización de la clase obrera; procurar su bienestar moral y material; proteger los derechos de los trabajadores; generar vínculos de solidaridad entre los miembros y fomentar la formación del orden social cristiano. Los COC tendían a declararse ajenos a la política partidaria ${ }^{25}$ sosteniendo que de esa manera podrían librarse de ser manipulados por los caudillos de turno. ${ }^{26}$ Sin embargo, esta distancia de la política no fue absoluta

25 Por ejemplo, en los estatutos del CCA se sostenía que: "El Círculo se declara completamente ajeno a la política de partidos. Como ciudadanos, los socios procurarán cumplir sus deberes cívicos según los imperativos de su conciencia y patriotismo". (Círculo de Obreros Católicos de Arequipa, 1922, Art $^{\circ}$ 7).

26 Por ejemplo, José Miguel La Rosa, quien fue en varias ocasiones presidente del CCA, sostenía que antes de la existencia de esta institución en Arequipa, "los obreros estaban acostumbrados a ver en las agrupaciones que antes se habían constituido, algo así como biombos políticos, que como era natural se venían abajo a las primeras escaramuzas que 
pues en ocasiones se admitía el apoyo a algún candidato para defender el "orden social católico"27 y al mismo tiempo procuraban establecer vínculos con el gobierno.

Los COC buscaron generar un sentido de identidad entre sus miembros y contribuir a desarrollar una cultura popular a través de veladas literarias, recitales, canciones, himnos y símbolos con temas obreros. Se crearon días especiales de celebración obrera en contraposición con los días celebrados por los de los anarquistas o socialistas ${ }^{28}$. Estas actividades educativas y culturales tenían, entre otros fines, formar líderes obreros dentro de un marco doctrinal católico. Tanto en este aspecto como en algunas de sus obras sociales, los COC adoptaron estrategias de captación y de organización parecidas a las utilizadas por otros movimientos obreros muy distantes desde el punto de vista ideológico, como fueron las asociaciones anarquistas y socialistas.

La formación doctrinal, intelectual y técnica fue considerada esencial. Para ello se crearon escuelas nocturnas a las cuales asistían los mismos obreros que no hubieran completado sus estudios y los hijos de los mismos. ${ }^{29}$ También se procuró construir bibliotecas populares dependientes de los COC. Asimismo periódicamente, tanto sacerdotes como laicos comprometidos daban conferencias sobre temas relacionados con la cuestión obrera. Ellas posteriormente eran publicadas en panfletos que eran repartidos entre los miembros. También cada COC buscó tener un periódico, el cual se convirtió en un instrumento esencial para la propagación de ideas.

realizaban sus jefes, quizá no tanto porque desde el principio hubieran tenido tales propósitos, sino porque los politiqueros no desperdiciaban jamás la oportunidad de acercarse zalameramente a esas agrupaciones, ofreciéndoles su apoyo a cambio más o menos velado de que los favorecieran en las elecciones políticas próximas con sus votos, y entonces como era natural ese corrosivo ejercía su influjo propio y la institución degeneraba para morir enseguida", en La Colmena, 19-III-1936.

27 En los estatutos del CCA se contemplaba la posibilidad de participar en política: "La Junta Directiva deliberará y después de maduro examen someterá al dictamen de la Junta General si alguna vez, en virtud de circunstancias particulares y de una manera transitoria, conviene o no actuar en política; y entonces será para defender los principios del orden social católico, y de ningún modo a favor de un caudillo. Para decidirse por el sí, se necesitan las dos terceras partes del total de los votos". (Círculo de Obreros Católicos de Arequipa, 1922, Art ${ }^{\circ} 7$ ).

28 Un ejemplo de ello fue que el CCA celebraba el día del obrero el 6 mayo, por ser la festividad de San José, en contraposición con el 19 de mayo que era una fecha simbólica para el socialismo. En el periódico del CCA, La Colmena, se narra una anécdota interesante al respecto. En La Colmena, 17-IV-1921.

29 En este aspecto existía una similitud con las universidades populares, pues en las escuelas nocturnas además de alfabetizar a los obreros en algunos casos se les daba una formación técnica y doctrinal, y muchos de los profesores eran universitarios o jóvenes profesionales voluntarios. 
Siendo uno de los objetivos centrales de los COC la búsqueda del bienestar moral y material del obrero, se consideró indispensable el desarrollo de obras sociales. Un aspecto constante fue la promoción del cooperativismo y del mutualismo a través de la creación de cajas de ahorro, montes de piedad, cooperativas de consumo y sociedades de socorros mutuos. En el caso del CCA, se desarrolló un proyecto habitacional que logró obtener dos subsidios del gobierno para construir un barrio obrero ${ }^{30}$. Adicionalmente, se crearon bolsas de trabajo para auxiliar a los miembros que habían quedado desempleados, y consultorios jurídicos para asesorar a los miembros en sus problemas laborales. Otro objetivo considerado importante fue la creación de centros de reunión y recreo, donde los obreros pudieran tener un sano esparcimiento, practicar deporte y estrechar los vínculos de fraternidad.

El más importante de los COC fue el de Arequipa. Según Peter Blanchard, el CCA fue la más influyente de las organizaciones obreras de la ciudad durante las dos primeras décadas del siglo (Blanchard, 1982: 18). Como ya se ha dicho, el CCA fue fundado en 1896 por el fraile franciscano Mariano Holguín, quien posteriormente se convirtió en obispo de Arequipa. Desde esta posición se convirtió en un protector y promotor de dicha institución. A lo largo de su historia el CCA tuvo dos periódicos: el quincenal La Abeja (1897-1907) y el semanario La Colmena (1920-1942). Este último se convirtió en uno de los periódicos obreros de mayor tiraje y duración en el sur peruano. Entre las obras más importantes del CCA estuvieron la Sociedad de Socorros Mutuos, una escuela nocturna, una biblioteca popular, el proyecto habitacional León XIII, una cooperativa de consumo, una sección dramática y un centro de esparcimiento (La Colmena, 19-III-1936). En numerosas conferencias se difundieron los contenidos de la doctrina social de la Iglesia.

Otro COC importante fue el del Cusco. Este fue fundado por los franciscanos de la ciudad en 1899. Hacia 1909 esta institución contaba con más de trescientos miembros y desde 1913 sostenía una escuela nocturna en donde llegaron a estudiar 250 hijos de miembros hacia 1925 (La Colmena, 25-IV-1925). Este COC mantenía estrechos vínculos con el obispo de Cusco, Pedro Farfán, quien fue su presidente honorario (La Colmena, 21-XI-1925). Aún no se ha estudiado cabalmente el impacto de esta institución en el Perú, sin embargo, es necesario destacar su permanencia a lo largo del tiempo. En 1999 el Congreso del Perú mandó una moción de felicitación al COC del Cusco por los cien años de su fundación ${ }^{31}$.

30 La primera piedra del barrio se puso el 28 de julio de 1921. En La Colmena, 20-VI-1925.

31 "Considerando: Que, el 30 de julio de 1899 se constituyó el Círculo de Obreros Católicos del Cusco, asociación cívica destinada a fomentar lazos de solidaridad entre sus socios y a realizar acciones en beneficio de la comunidad. Que, a lo largo de su centenaria vida institucional, el Círculo de Obreros Católicos del Cusco se ha enraizado en la vida social de la 
En Lima, el padre Jorge Dinthilac creó el Centro Católico Obrero en 1913. Apoyado por los religiosos de la Congregación de los Sagrados Corazones, el Centro pudo realizar un conjunto de obras. Se publicó un periódico, El Obrero /dea ${ }^{\beta 2}$, se creó una escuela nocturna, se fundó una cooperativa y una asociación de socorros mutuos (Variedades, 15-III-1924).

En Ayacucho existió un COC que fue activo por lo menos desde 1916 hasta 1933. Hacia 1920 aparentemente logró tener 350 miembros y al igual que otros COC patrocinó una biblioteca pública, una escuela nocturna, una asociación de socorros mutuos y una caja de ahorros (La Colmena, 1-VII-1920). También publicó un periódico bimensual, La Hormiga, en el cual además de difundir los principios de la doctrina social de la Iglesia se denunciaron diversos problemas sociales de Ayacucho (La Hormiga, 28-XII-1933).

En Puno se creó un COC probablemente a fines de la década de 1920 y aparentemente tuvo una influencia relativamente importante a nivel local. Fue fundado por el obispo de la ciudad, Fidel Cosío. Aquí se creó una oficina de asistencia legal, una biblioteca pública y un centro de formación cultural (La Colmena, 15-II-1930).

Además de los COC, numerosos obreros católicos tuvieron la tendencia a formar pequeñas sociedades modeladas en torno a las antiguas confraternidades y gremios coloniales. Ellas generalmente fueron patrocinadas por alguna orden o congregación religiosa, entre las que destacaron los franciscanos, salesianos, dominicos, jesuitas y sagrados corazones, quienes en algunos casos crearon escuelas técnicas para la formación de artesanos y obreros. Este fue el caso de algunas sociedades en Lima, como la Congregación de Artesanos de San José fundada en 1908 por el padre José Antonio Pérez Barba S.J. (el nombre de esta asociación cambió a Círculo de Obreros de San José en 1930) (El Bien Social, 11-V-1908); la Liga de San Alfonso, fundada por el redentorista Eugenio Pernin antes de 1908, dedicada a la "moralización e instrucción" de la clase obrera (El Bien Social, 7-VII-1908); la Sociedad de Trabajadores del Sagrado Corazón de Jesús fundada por los padres dominicos en Arequipa y luego se extendió a Lima. En 1931 llegó a tener quinientos miembros y fue la base de la posterior Federación de Sociedades de Obreros Católicos, fundada en 1932 (Klaiber, J., 1988: 241).

ciudad del Cusco, por haber efectuado una serie de actividades provechosas, entre las que destacan su permanente preocupación por la educación y la cultura. Se propone: Saludar al Círculo de Obreros Católicos del Cusco al cumplir el 30 de julio del presente año, un siglo de vida institucional, e igualmente saludar en la persona de su Presidente don Rubén E. Farfán Cárdenas a todos y cada uno de los socios de la institución, haciendo votos porque esta efeméride centenaria se convierta en un estímulo para la continuidad y engrandecimiento de la institución". ("Círculo de Obreros Católicos", 1999).

32 Ver El Obrero Ideal, II-1914. 
En provincias también se fundaron numerosas asociaciones similares como fue la Unión Pía de Trabajadores Salesianos, fundada por los salesianos de Cusco, la cual creó una escuela técnica para niños (Arrieta, 1914: 8).

El catolicismo social también tuvo influencia en algunas asociaciones obreras no confesionales como fueron los casos de la Sociedad Fraternal de Empleados y Obreros del Ferrocarril y el Centro Social Obrero de Arequipa. La primera tuvo dentro de su estructura una asociación Pro Catecismo y se organizaron un conjunto de conferencias sobre temas obreros desde la perspectiva de la doctrina social católica (El Deber, 27-VII-1917). Por otro lado, el Centro Social Obrero llevó a cabo algunas de sus actividades en conjunto con el CCA, aunque manteniendo su independencia (La Colmena, 17-IV-1921). Una investigación más amplia podría indagar acerca de cuál fue la influencia del catolicismo social en sociedades similares. También sería importante el estudio de la intensa labor social de algunos obispos, religiosos y asociaciones laicas que tuvieron un impacto en la clase obrera a través de la creación de escuelas técnicas, cajas de ahorro, ligas de temperancia y sociedades de socorros mutuos.

\section{Balance final}

En 1927, a raíz de la celebración del trigésimo primer aniversario de la fundación del CCA, el padre Francisco Cabré O.F.M. hizo un detallado examen sobre la labor de dicha institución a lo largo de su historia y de sus perspectivas hacia el futuro. Señalaba que uno de los méritos del CCA había sido el haberse constituido en la primera organización obrera y popular católica durante la república. Sin embargo, tomando en cuenta los cambios existentes en la sociedad, el CCA debía evolucionar o estaría condenado a desaparecer. Consideraba que la labor educativa y mutualista no era suficiente para lograr una influencia importante en la clase obrera ni para contrarrestar el avance cada vez más grande del socialismo. Planteaba que los COC debían convertirse en sindicatos que deberían luchar contra "la tiranía del socialismo y contra los excesos del capital cuando este no cumple su deber". Pero para ello debían crearse nuevos cuadros de obreros católicos que estuvieran comprometidos con los cambios sociales y con la cristianización del mundo obrero. Los COC, con sus numerosas obras, debían convertirse en matrices que formaran en el futuro un verdadero sindicalismo católico (La Colmena, 19-III-1927).

Las reflexiones del padre Cabré testimonian de los alcances y limitaciones de las organizaciones obreras católicas en el país. Si bien los COC no lograron generar un movimiento masivo como en otros países latinoamericanos y en Europa, algunos perduraron a lo largo de varias décadas, generaron un arraigado sentido de identidad entre sus miembros, desarrollaron obras sociales y participaron en el debate político-laboral de su tiempo. Es necesario resaltar que durante las tres primeras décadas del siglo XX ningún partido ni 
ideología logró tener un control hegemónico sobre el movimiento obrero ${ }^{33}$. El catolicismo social y los COC tampoco lo tuvieron. Sin embargo, desarrollaron una presencia católica en la clase obrera a través de distintos medios como periódicos, conferencias y participando en algunas de las luchas laborales. En ese sentido los COC representaron iniciativas concretas y alternativas de participación en la cuestión social y en la formación de una cultura cívica y democrática entre las clases trabajadoras.

Esta situación cambió con el advenimiento de los movimientos políticos de carácter masivo en el Perú desde la década de 1930. Ellos lograron desplazar a las asociaciones obreras que no llegaron a convertirse en sindicatos con una base partidaria. En este contexto, la presencia de los COC necesariamente se vio reducida dentro del mundo laboral peruano. Sin embargo, aún está por estudiarse el grado de difusión e influencia de las propuestas y proyectos social-católicos en la legislación laboral y en las asociaciones obreras que surgieron posteriormente en Perú.

\section{Referencias bibliográficas}

\section{Fuentes Primarias}

a) Periódicos

El Bien Social, Lima, 1908.

El Deber, Arequipa, 1917.

El Obrero Ideal, Lima, 1914.

La Colmena, Arequipa, 1921, 1927, 1930 y 1936.

La Hormiga, Ayacucho, 1933.

Variedades, Lima, 1924.

\section{b) Impresos}

Arrieta, A. (1914). Conferencia dada a los cooperadores salesianos por el R.P. Fr. Angel de Jesús Arrieta O.F.M. el día 27 de setiembre de 1914 en el salón del Círculo de Obreros Católicos. Cusco: Tip. Americana.

33 Es innegable que primero el anarquismo y luego el socialismo tuvieron una influencia central en el desarrollo del movimiento obrero peruano pero sus principios estuvieron lejos de ser asumidos de manera integral por la clase obrera, la cual más bien los usó de manera instrumental para lograr una serie de reformas laborales. Ello puede verse en la tesis doctoral de Paulo Drinot (2000), quien analizó la relación entre el movimiento obrero, el Estado y las ideologías radicales a partir de la experiencia y percepción de los cambios sociales que tuvieron los obreros peruanos en este periodo. 
Asamblea Episcopal del Perú (1922). La Acción Social Católica en el Perú (Ensayo) Principios, Hechos i Normas. Informe de la Comisión, nombrada por la Asamblea Episcopal del Año 1921. Lima: Imp. De los Huérfanos.

Bermejo, J. (1914). Conferencia dada por el reverendo padre José Bermejo S.J. al círculo de Obreros Católicos de Arequipa, el 31 de mayo de 1914. Arequipa: Tip. Cáceres.

Cabré, F. (1918). La Unión de la Clase Obrera. Conferencia dada al "Círculo de obreros católicos" en el cine Arequipa, el día 27 de enero de 1918, por el R.P. Francisco Cabré O.F.M. Misionero descalzo, sub-director del mismo círculo y socio numerario de "Acción Pupular" de Barcelona. Arequipa: Tip. Cáceres.

Círculo de Obreros Católicos de Arequipa (1901). Estatutos del Círculo de Obreros Católicos de Arequipa. Aprobado en Sesión de Junta General del 6 de octubre de 1901. Arequipa: Cáceres.

Círculo de Obreros Católicos de Arequipa (1922). Estatutos de Círculo de Obreros Católicos de Arequipa y Reglamento de la Sección de Socorros Mutuos. Discutido y aprobado en la sesión de la Junta General de 5 de Febrero de 1922. Arequipa: Cartig \& Rivera S.A.

Drinot, P. P. (1928). Manual de Acción Católica. Dedicado al Pueblo Peruano. Opúsculo de Propaganda y Defensa Social Recomendado a los Fieles Católicos del Perú, por el VIII Concilio Limense. Lima: Talleres Gráficos La Tradición.

García, M. (1913). Conferencia dada al Círculo de Obreros Católicos por Mariano N. García, Canónigo Tesorero el 30 de marzo de 1913. Cusco: Imprenta Americana.

González Prada, M. (1964). Horas de lucha. Lima: Fondo de Cultura Económica -Ediciones "Futuro".

Guinness, G. (1909). Peru; its story, people and religion. London: Morgan \& Scott, Ltd. León XIII (1891). Rerum Novarum.

Margañón, J. (1912). La Honradez del Obrero. Dedicada al Círculo de Obreros Católicos de Arequipa en el XVI Aniversario de su fundación. Arequipa: Tip. Medina.

Polar, C. (1912). Propaganda Popular de la Verdadera y Sana Filosofía Social a favor de los obreros. Arequipa: Editores Orellana.

Primer Congreso Católico del Perú (1897). Anales del Primer Congreso Católico del Perú. Lima: Imprenta de la Librería Clásica y Científica.

Primer Congreso Interdiocesano de Acción Social, P. C. I. de A. (1921). Primer Congreso Interdiocesano de Acción Social: Homenaje a la patria en el Primer Centenario de la Independencia. Cusco: Tipografía Americana. 
Vargas, I. (1936). Apuntes críticos sobre asuntos indigenistas. Cusco: Tipografía Americana.

Vargas, I. (1937). Conferencias y discursos. Cusco: Tipografía Americana.

Vargas, I. (1947). La democracia auténtica y la encíclica "Rerum Novarum" de León XIII. Cusco: Tipografía Americana.

Vargas, I. (1948). Recopilaciones psico-sociológicas de mis apuntes críticos sobre asuntos indigenistas para el II Congreso Indigenista Interamericano del Cusco, III sección Socio-económica. Arequipa: Tipografía Americana.

Vargas, I. (1952). Conferencias y discursos. Tercera Serie, con apéndice de artículos periodísticos. Cusco: Tipografía Americana.

VII Concilio Limense, S. C. P. (1913). Constituciones del VII Concilio Provincial de Lima. Celebrado el año de 1912 bajo la presidencia del Iltmo. y Rdmo. Mons. Dr. D. Pedro Manuel García. Lima: Casa Editora Sanmarti.

VIII Concilio Limense, O. C. P. (1934). Decretos del VIII Concilio Provincial Limense celebrado en Lima, el año 1927 bajo la presidencia del Exmo. Mons. Emilio Lisson y promulgado el 27 de abril de 1934 por el Exmo. Mons. Pedro Pascual Farfán, XXVIII Arzobispo de Lima. Lima: Editora Sanmarti y Cia.

\section{Fuentes secundarias}

\section{a) Artículos}

Círculo de Obreros Católicos (7-VI-1999). Revisado el 12-VIII-2016, a partir de http://www4.congreso.gob.pe/congresista/2001/destrada/gestion-95-99/mociones.htm

Cubas Ramacciotti, R. (2008). "Catolicismo y movimiento obrero en el Perú: El caso de los Círculos de Obreros Católicos (1890-1930)", en Armas Asín, Fernando, Carlos Aburto, Juan Fonseca y José Ragas (Eds.), Políticas divinas: Religión, diversidad y política en el Perú contemporáneo. Lima: Pontificia Universidad Católica del Perú, Instituto Riva-Agüero, pp. 229-250.

Lynch, J. (1991). "La Iglesia Católica en América Latina, 1830-1930", en L. Bethell (Ed.), Historia de América Latina. 8. América Latina: cultura y sociedad, 18301930. Barcelona: Cambridge University Press, Editorial Crítica, Vol. 8, pp. 65-122.

McCartin, J., \& McCartin, J. (2007). "Working-class Catholicism: A call for new investigations, dialogue and reappraisal", en Labor Studies in Working-Class History of the Americas, 4(1), pp. 99-110.

Strikwerda, C. (1988). "The Divided Class: Catholics vs. Socialists in Belgium, 1880-1914", en Comparative Studies in Society and History, 30(2), pp. 333-359. 


\section{b) Libros}

Aldea Vaquero, Q., García Granda, J., y Martín Tejedor, J. (1987). Iglesia y sociedad en la España del siglo XX: Catolicismo social (1909-1940). Madrid: Consejo Superior de Investigaciones Científicas, Centro de Estudios Históricos, Departamento Enrique Flórez.

Balbi Scarneo, C. R. (1989). Identidad clasista en el sindicalismo: su impacto en las fábricas. Lima: DESCO.

Basombrío Iglesias, C. (1982). El movimiento obrero: 1940-56 en la lucha por la democracia. Lima: Tarea.

Basombrío Iglesias, C., y Sagástegui L., W. (1984). El movimiento obrero: 1956-62 frente a la convivencia. Lima: Tarea.

Blanchard, P. (1982). The origins of the Peruvian labor movement, 1883-1919. Pittsburgh: University of Pittsburgh Press.

Burga, M., \& Flores Galindo, A. (1980). Apogeo y crisis de la República Aristocrática. Lima: Ed. Rikchay.

Castillo, J. J. (1977). El sindicalismo amarillo en España: aportación al estudio del catolicismo social español (1912-1923). Madrid: Editorial Cuadernos para el Diálogo.

Ceballos Ramírez, M. (1991). El Catolicismo Social: Un tercero en discordia. Rerum Novarum, la "cuestión social" y la movilización de los católicos mexicanos (18911911). Mexico D.F.: El Colegio de México.

Contreras, C., y Cueto, M. (2013). Historia del Perú contemporáneo. Desde las luchas por la independencia hasta el presente. $5^{\mathrm{a}}$ ed. Lima: IEP, Fondo Editorial PUCP, Universidad del Pacífico: Centro de Investigación.

Drinot, P. (2000). Workers, the State, and Radical Politics in Peru in the Early 1930s. University of Oxford, Oxford.

Drinot, P. (2011). The allure of labor: workers, race, and the making of the Peruvian state. Durham: Duke University Press.

Flores Galindo, A. (1983). Los mineros de la Cerro de Pasco 1900-1930 (2a ed). Lima: PUCP. Fondo Editorial.

Gibson, R. (1989). A social history of French Catholicism, 1789-1914. London y New York: Routledge.

Klaiber, J. (1988). La Iglesia en el Perú: su historia social desde la independencia. Lima: Fondo Editorial de la Pontifícia Universidad Católica del Perú. 
Klarén, P. (2004). Nación y sociedad en la historia del Perú. Lima: Instituto de Estudios Peruanos.

Melgar Bao, R. (1980). Burguesía y proletariado en el Perú, 1820-1930. Lima: C.E.I.R.P.

Misner, P. (1991). Social Catholicism in Europe. From the Onset of industrialisation to the First World War. London: Longman and Todd.

Montero García, F. (1983). El primer catolicismo social y la Rerum Novarum en España, 1889-1902. Madrid: CSIC.

O'Leary, D. (2000). Vocationalism and social Catholicism in twentieth-century Ireland: the search for a Christian social order. Dublin, [Ireland]; Portland, OR: Irish Academic Press.

Pareja Pflucker, P. (1980). Aprismo y sindicalismo en el Perú: 1943-1948. Lima: Rikchay.

Pareja Pflucker, P. (1985). El movimiento obrero peruano de los años 30. Lima: Fundación Friedrich Ebert.

Pazos, A. M. (1993). Un siglo de catolicismo social en Europa 1891-1991. Pamplona: EUNSA.

Ponce de León, M. (2011). Gobernar la pobreza. Prácticas de caridad y beneficencia en la ciudad de Santiago, 1830-1890. Santiago: Editorial Universitaria, DIBAM, Centro de Investigaciones Barros Arana.

Portocarrero, J. (1987). Sindicalismo peruano: primera etapa 1911-1930. Lima: Gráfica Labor.

Stein, S. J. (1980). Populism in Peru: the emergence of the masses and the politics of social control. Madison: The University of Wisconsin Press.

Stein, S., y Miller, L. (1986). Lima obrera: 1900-1930. Lima: El Virrey.

Sulmont, D. (1975a). El movimiento obrero en el Perú. 1900-1956. Lima: Pontificia Universidad Católica del Perú.

Sulmont, D. (1975b). Sindicalismo y política en el Perú: primera parte. Lima: PUCP, Taller de Estudios Urbanos Industriales.

Tejada, L. (1988). La cuestión del pan: El anarco sindicalismo en el Perú, 18801919. Lima: Instituto Nacional de Cultura.

Vidler, A. R. (1964). A century of social Catholicism, 1820-1920. London: S. P. C. K. 